\title{
Alkyl Tail Segments Mobility as a Marker for Omega-3 PUFA-rich Linseed Oil Oxidative Aging
}

\author{
Maysa Resende ${ }^{1}$, Charles Linder ${ }^{1}$, and Zeev Wiesman ${ }^{1}$ \\ ${ }^{1} \mathrm{BGU}$
}

May 5, 2020

\begin{abstract}
The goal of the present study is to demonstrate $1 \mathrm{H}$ LF-NMR time relaxation measurements for efficient and rapid evaluation of Omega-3 polyunsaturated fatty acids (PUFA)-rich linseed oil (LSO) oxidative aging mechanisms, by monitoring primary chemical and structural changes occurring during thermal oxidative stress. The LF NMR monitors the different proton spinspin coupling energy relaxation times, T2 within LSO molecular segments, from the initiation of free radical generation and hydroperoxide formation to the propagation of alkoxy radicals, and alpha, beta-unsaturated aldehydes formation, and a termination phase of crosslinked polymerization end products. The $1 \mathrm{H}$ LF NMR T2 values monitors both the covalent and secondary bonding interactions (e.g., electrostatic and hydrogen bonding) during the different oxidation phases. The present paper shows that LSO tail segments mobility in terms of T2 multi-exponential relaxation decays, generated by data reconstructing of $1 \mathrm{H}$ transversal relaxation components are providing a clear, sharp and informative understanding of LSO sample's autoxidation aging processes. This is supported by high field band selective $1 \mathrm{H}$ NMR pulse excitation for hydroperoxide and aldehydes quantification of the same LSO samples at 25, 40, 60, 80, 100, and $120 \mathrm{oC}$ with pumped air for 168 h. Peroxide value, viscosity and self-diffusion, as well as fatty acids profile and by- products determined by GC-MS were also carried out, and correlated with the LSO tail T2 relaxation results. In conclusion the selective determination of LSO alkyl tail T2 energy relaxation time domain values was demonstrated as a rapid evaluation marker for following omega-3 PUFA-rich oils oxidative aging.
\end{abstract}

\section{Introduction}

Linseed oil (LSO) contains high levels of omega-3 polyunsaturated fatty acid (PUFA), and lesser amounts of other fatty acids (e.g., of 48-60\% of linolenic acid (18:3), 14-19\% of linoleic acid (18:2), and mono and nonsaturated $14-24 \%$ of oleic acid (18:1), 3-6\% of stearic acid (18:0) and 6-7\% of palmitic acid (16:0) (Lazzari and Chiantore, 1999). LSO is used in various industries (e.g., paints, wood finish, linoleum production, nutritional supplements and foods) wherein the LSO's autoxidation aging processes is an important product factor that are influenced by the air/oxygen supply, and elevated temperatures resulting in some cases in a viscous gel like semi-solid end product (Zhang et al., 2012; Kaleem et al, 2015). It is well established that oxidation takes place by a free radical mechanism on the polyunsaturated fatty acid's double bonds and tail segments of the alkyl chain resulting in some low molecular weight molecules and cross-linking polymerization of components forming 3D networks (Zhang et al., 2012; Douny et al., 2016). A considerable amount of research has been performed on elucidation of the autoxidation mechanism, since lipid oxidation is important for numerous products and is also known to result in wood and linoleum fires, food spoilage, and biologically tissue injuries and degenerative diseases (Gorkum and Bouwman, 2005; Budularto and Kamal-Eldin, 2015).

PUFAs are highly susceptible to thermal autoxidation due to the presence of readily removed bisallylic hydrogen atoms (Zhang et al., 2012; Vieira et al., 2017), of relatively low bond dissociation energies of about $71 \mathrm{KJmole}^{-1}$ (Juita et al., 2013), resulting in radical chain initiation of decomposition and crosslinking polymerization reactions (Gorkum and Bouwman, 2005). The LSO omega-3 PUFA-rich oxidative thermal 
aging process is demonstrated in Scheme 1. Initial formation of lipid peroxide on a LSO linolenic acid bisallylic carbon 11 is followed by a molecular rearrangement yielding conjugated diene. Oxygen uptake initially forms a hydroperoxide that initiates the propagation phase, with similar chain reactions of the surrounding PUFAs. The propagation phase terminates with cleavage of the PUFA alkyl tails and release of alpha, beta unsaturated aldehydes (e.g., acrolin (2-propenal), cortonaldehyde (2-butenal; 4-hydroxy-trans-2nonenal (HNE); 4-hydroxy-trans-2-hexanal (HHE); malonaldehyde (MDA)). Previous research showed that in heated vegetable oils with PUFA components, significant concentrations of these aldehydes could be generated (Vieira et al., 2017). Small amounts of the low molecular weight aldehydes are volatized and large amounts of polymerized by crosslinking, nonvolatile viscous products remain in the oxidized oil sample (Gorkum and Bouwman, 2005).

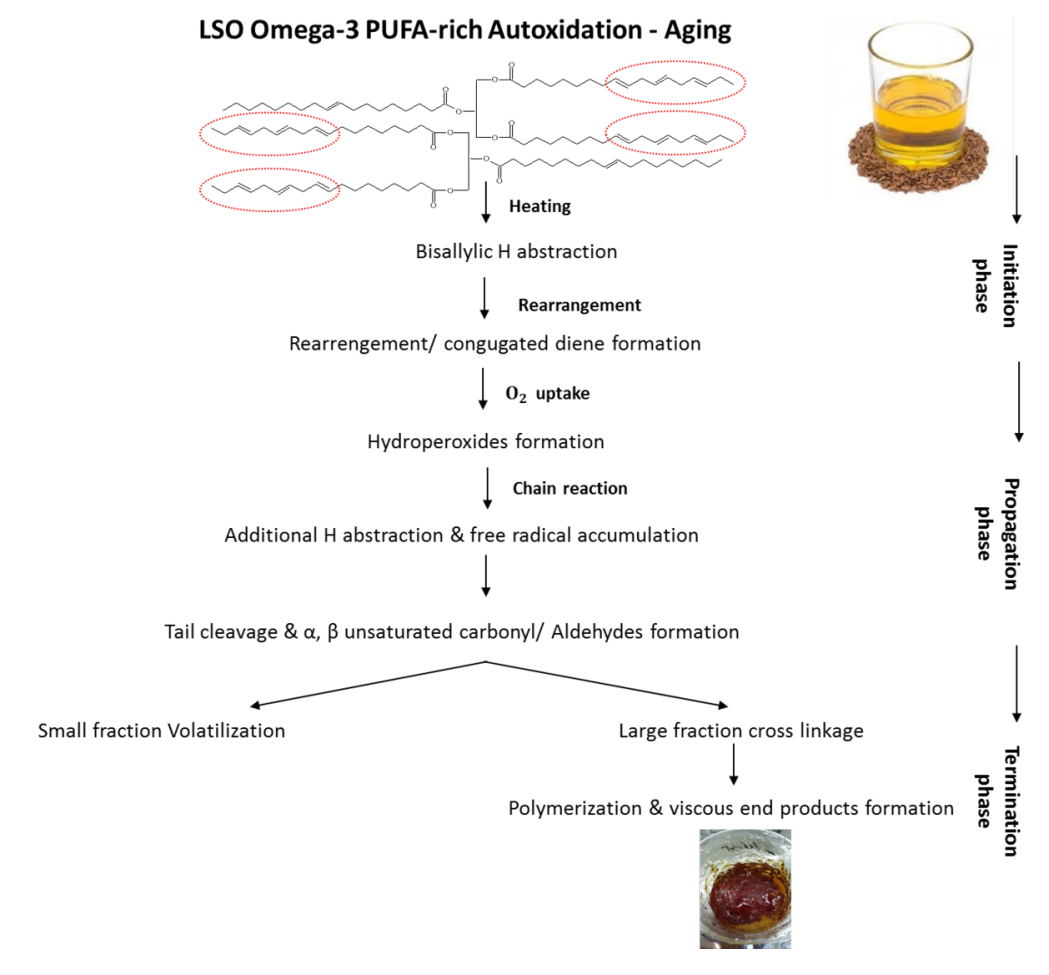

Scheme 1 LSO omega-3 PUFA-rich thermal aging process

Numerous chemical and physical analytical methods have been developed to asses lipid oxidation such as conjugated diene value, peroxide value (PV), alcohols, epoxides, $p$-anisidine assay, HBR titration, iodometric titration, xynol orange, total polar components (TPC), high performance liquid chromatography (HPLC), fatty acid composition determined by gas chromatography-mass spectrometry (GC-MS), Fourier transformation infrared spectroscopy (FTIR), volatile product determination by gas chromatography, dimer/polymers by size exclusion chromatography (SEC), and electron spin resonance (ESR) (Jacobsen, 2015; Hwang et al., 2017, Velasco et al., 2005). There is however a lack of consistency in many of the results, because most of these analytical methods are designed to detect one type of oxidation product while lipid oxidation is a very complicated process producing numerous products at different times of oxidation. Hence, as suggested in Hwang et al. (2017) comprehensive review, the development of methods that combine the concomitant detection of different types of oxidation products is necessary for the consistent assessment of lipid oxidation. Two important questions were raised by this researcher: which oxidation product best represents a given stage of the lipid's oxidation? And which analytical method should be used? In this respect, as described below LF- ${ }^{1} \mathrm{H}-\mathrm{NMR}$ spectroscopy technology has significant potential, as shown in this paper, in elucidating molecular structures of oxidation products from lipids and in revealing the mechanisms of lipid oxidation. 
The field of ${ }^{1} \mathrm{H}$ LF-NMR energy time relaxometry is a powerful tool for identifying molecular species and to study their dynamics even in complex materials (Berman et al., 2013a; 2015; Wiesman et al., 2018; Resende et al., 2019ab; Rudszuck et al., 2019). This relates to the measurement of energy time relaxation values as a consequence of interactions among nuclear spins and between spins and their surroundings (matrix). Longitudinal magnetization returns to equilibrium following application of a radio frequency pulse because of energy transferred to the lattice (spin-matrix interactions), and transverse relaxation arises from spin-spin interactions following a $90^{\circ}$ pulse. The time constants for longitudinal and transverse energy relaxations are $\mathrm{T}_{1}$ and $\mathrm{T}_{2}$ respectively (Berman et al., 2013b). Relaxation time distribution experiments range from simple and rapid one dimensional (1D) tests (T1 or T2) to more complicated multidimensional ones (e.g., $\mathrm{T}_{1}$ vs. $\mathrm{T}_{2}$ ). 1D tests use constant intervals between pulses, allowing for either longitudinal or transverse relaxation to be evaluated, whereas in multidimensional experiments, the signal is measured as a function of two or more independent variables, allowing the spin system to evolve under different relaxation mechanisms (Song et al., 2002, Berman 2013b). By assuming a continuous distribution of exponentials, a relaxation time distribution of exponential coefficients is achieved with components appearing as peaks. This is an ill-posed Inverse Laplace Transform (ILT) problem. The common mathematical solution implemented today, for both 1D and 2D data, is based on $L_{2}$-norm regularization (Song et al., 2002; Graham, et al., 1996; Berman et al., 2013b, Campisi-Pinto et al., 2018).

Current technologies are not effective in characterizing the morphological and chemical structural domains of saturated, monounsaturated fatty acids (MUFA) and PUFA materials, or how the morphological structures of fatty acids, at the meso, nano, and molecular levels, affect their oxidation mechanisms. ${ }^{1} \mathrm{H} \mathrm{LF}-\mathrm{NMR}$ energy relaxation time technology consisting of L1/L2 norm regularization (Campisi et al. 2018, 2019; Resende et al., 2019a,b), is proposed as a tool to analyze PUFA oils undergoing thermal oxidation. This technology can generate two-dimensional (2D) chemical and morphological spectra using a recently modified and developed primal-dual interior method for the convex objectives (PDCO) optimization solver for computational processing of the energy relaxation time signals $T_{1}$ (spin-lattice) and $T_{2}$ (spin-spin): With carefully chosen reconstruction parameters, the data signals can be reconstructed into $2 \mathrm{D}$ graphics of the different energy relaxation times assigned to the mobility of different chemical structures, and their adjacent environments (Wiesman et al., 2018). This reconstruction of LF-NMR signals into two and three dimensional (2D and 3D) $T_{1}$ vs. $T_{2}$ graphs is able to effectively characterize the chemical and morphological domains of complex materials (Wiesman et al., 2018). The $2 \mathrm{D}$ graphical maps of $\mathrm{T}_{1}$ vs. $\mathrm{T}_{2}$ generated for butter, rapeseed oil, soybean oil, and linseed oil show that the different degrees of unsaturation of fatty-acid oils affect their chemical and morphological domains, which influences their oxidative susceptibility (Resende et al., 2019a). The technology of the ${ }^{1} \mathrm{H}$ LF-NMR energy relaxation time proved to be an effective tool to characterize and monitor PUFA oxidation (Resende et al., 2019a). The use of $2 \mathrm{D}$ graphic reconstruction of $\mathrm{T}_{1}$ vs. $\mathrm{T}_{2}$ as compared to only one dimensional (1D) has the ability to increase peak separation on the diagonal $\left(\mathrm{T}_{1}=\mathrm{T}_{2}\right)$ and when new polymerized oxidation products new peaks appear below the diagonal (same constant $\mathrm{T}_{1}$ but decreased $\mathrm{T}_{2}$ ) during later stages of the oxidation process (Resende et al., 2019a,b).

Methods using high field ${ }^{1} \mathrm{H}$ NMR relaxation were found by Sun and Moreira (1996), Hein et al (1998), Sun et al. (2011) and Bakota et al (2012) to correlate well with various parameters associated with lipid oxidation (e.g., free fatty acid; polar materials in heated oils; solid fat content (SFC approved as AOCS Cd 16b-93)). It was proposed by Hwang et al. (2017) that "there are molecular structure and composition changes in oil during oil oxidation and degradation process affecting the chemical environment surrounding the protons. Thus the proton mobility affecting the NMR energy relaxation time values changes as oil degrades".

High field ${ }^{1} \mathrm{H}$ NMR was also used to analyze aldehydes produced in various heated oils (Guillen and Uriarte, 2009). These researchers reported on the ability to analyze a list of aldehyde products in linseed oil heated at $190^{\circ} \mathrm{C}$ for $20 \mathrm{~h}$, and also determined acyl groups' iodine value and polar compounds. Merkx et al. 2018 reported a broad band selective ${ }^{1} \mathrm{H}$ NMR method for determination of both hydroperoxides and aldehydes in oxidized oils. Furthermore, based on electron spin resonance (ESR) system, combined with free radical standard and trapping agents (TEMPO and PBN) was released for determination of peroxides in the early fast initiation phase of oil oxidation (Velasco et al., 2005). Blumich (2016) developed compact ${ }^{1} \mathrm{H}$ LF - 
NMR systems and Guilleux et al. (2016) developed an automate LF-NMR system. However, one of the remaining problems of ${ }^{1} \mathrm{H} L F-\mathrm{NMR}$ and especially $2 \mathrm{D} \mathrm{T}_{1}-\mathrm{T}_{2}$ systems is the relatively long experimental and data processing time required to finalize the results. Therefore these systems are not yet suitable for high throughput applications such as real-time reaction monitoring or rapid screening of oil oxidation (Hwang et al., 2017).

In the present study the objective is to develop a non-sample modifying ${ }^{1} \mathrm{H}$ LF-NMR energy time relaxation sensitive application supported with other techniques (e.g., HF NMR, GC-MS and viscosity) to evaluate LSO oxidative aging processes, based on monitoring the main chemical and structural changes occurring during thermal oxidative reactions. As for example by following the alkyl tails $\mathrm{T}_{2}$ values it is possible to correlate the degree of olefin functionality and the ratio of the olefin components with the different degrees of functionality that control the onset of crosslinking polymerization and gel structure formation. We demonstrate below the capability of using the rapid ${ }^{1} \mathrm{H} \mathrm{T}_{2}$ energy relaxation time technology to monitor LSO molecular segments mobility. In particular the monitoring of the LSO aliphatic tail's relaxation was used to follow the chemical and structural changes in all the autoxidation aging phase; starting from the initiation phase (abstraction of hydrogen, fatty acid chain rearrangement and oxygen uptake yielding of hydroperoxides production), the propagation phase (chain reactions resulting in tail cleavage to form alkoxy radicals, and alpha, betaunsaturated aldehydes formation), and the termination phase (cross linking formation of polymerized end products).

\section{Materials and methods}

\section{Materials}

All chemicals and reagents used in this study were analytical grade. Linseed oil was purchased from a local supplier (Nes Shemanim, Israel) and was stored in a sealed container in a dark room at ${ }^{\sim} 20^{0} \mathrm{C}$ room temperature.

\section{Experimental system}

Autoxidation experimental design was based on previous studies (Resende et al. 2019ab; Weisman et al., 2018; Berman et al., 2016; Meiri et al., 2015). Briefly, six samples of $250 \mathrm{ml}$ of linseed oil in $500 \mathrm{ml}$ beakers were heated in a hot plate at different temperatures $(25,40,60,80,100$ and $120 \mathrm{degC})$. Air was pumped into the beaker with maximum magnetic stirring for up to 168 hours. Before the induced autoxidation process (time 0 ) and after time periods of 3, 6, 9, 24, 48, 72, 96, 120 and 168 hours of heating, a $20 \mathrm{~mL}$ sample was removed into a vial which was placed in cold water for 10 min and then stored sealed at -20 degC to avoid further oxidation prior to analysis.

\section{LF-NMR relaxation}

The spin-spin ${ }^{1} \mathrm{H}$ LF NMR measurements were carried out with a Maran bench-top pulsed NMR analyzer (Resonance Instruments, Witney, UK) with a permanent magnet and an $18 \mathrm{~mm}$ probe head operating at $23.4 \mathrm{MHz}$.

Before each measurement, the samples were stabilized at $40 \mathrm{degC}$ for $40 \mathrm{~min}$ and then allowed to equilibrate inside the instrument for $5 \mathrm{~min}$. The spin-spin relaxation time constant $\left(\mathrm{T}_{2}\right)$ was generated using a CarrPurcell-Meiboom-Gill (CPMG) pulse sequence. The CPMG sequence consists in applying a 90 degree radiofrequency pulse to the sample, followed by many 180 degree pulses. Each time a 180 degree pulse was applied, the signal decay of the magnetic field was removed and a single data point was acquired (Carr and Purcell, 1954; Meiboom and Gill, 1958).

For all the samples 32 scans were accumulated. The number of echoes acquired was 16,384 with a recycle delay of $6 \mathrm{~s}$ and $\tau$ between 200 to $550 \mu$ s. Receiver gain (RG) and magnetic field were calibrated before each measurement. The signal processing was based on the PDCO inverse Laplace transform optimization algorithm with $a_{2}=0.5$ (Berman et al., 2013b; Campisi-Pinto et al., 2018) 
The self-diffusion measurements were carried out with a $20 \mathrm{MHz}$ minispec bench-top pulsed NMR analyzer (Bruker Analytic GmbH, Germany), equipped with a permanent magnet, and a 10-mm temperature controlled probe head according to Meiri et al. (2015). Prior to each measurement, the samples were stabilized at $40^{\circ} \mathrm{C}$ for $40 \mathrm{~min}$ and then allowed to equilibrate inside the instrument for $5 \mathrm{~min}$.

The self-diffusion coefficient, D, was determined by the pulsed-field gradient spin echo (PFGSE) method (Stejskal and Tanner, 1965). The pulse sequence was used with 16 scans, $\tau$ of $7.5 \mathrm{~ms}$, and a recycle delay of $6 \mathrm{~s}$. Typical gradient parameters were $\Delta$ of $7.5 \mathrm{~ms}, \delta$ of $0.5 \mathrm{~ms}$, time between the $90^{\circ}$ pulse to the first gradient pulse of $1 \mathrm{~ms}$, and $G$ of $1.6 \mathrm{~T} / \mathrm{m}$. Each reported value of the self-diffusion coefficient (D) is the average of a minimum of ten measurements.

\section{Quantitative NMR (Hydroperoxides and aldehydes)}

For the high-resolution (HF) ${ }^{1} \mathrm{H}$ NMR quantification of both hydroperoxides and aldehydes in the LSO samples the procedure reported by Merkx et al. (2018) was applied. Two aliquots were used per sample and time point. Single pulse and band selective spectra were recorded on a Bruker Avance III $600 \mathrm{MHz}(14.1 \mathrm{~T})$ NMR spectrometer (Bruker BioSpin, Switzerland) equipped with a $5 \mathrm{~mm}$ BBI-probe or an Avance III 600 $\mathrm{MHz}$ spectrometer equipped with a $5 \mathrm{~mm}$ cryo-probe. The internal temperature of the probe was set at 295 $\mathrm{K}$. The single pulse experiments were recorded with $4 \mathrm{scans}$, a relaxation time of $5 \mathrm{~s}$, and an acquisition time of $4 \mathrm{~s}$. The $90^{\circ}$ pulse length was determined automatically $(7.2 \mu \mathrm{s})$, and the receiver gain was set to the maximum value. The band-selective pulse used a double echo with gradients using selective refocusing with a RE-BURP shaped pulse and a $90^{\circ}$ pulse in between the $180^{\circ}$ pulses to refocus J-evolution. The length of the shaped pulses was 1-2 ms, and band-selective spectra were recorded with 16 scans. The relaxation and acquisition times were respectively set to 5 and $2.7 \mathrm{~s}$, the $90^{\circ}$ pulse length was determined automatically $(7.2 \mu \mathrm{s})$. The data was processed with Bruker TopSpin 3.2 software. Before Fourier transformation, an exponential window function with a line-broadening factor of 0.3 was applied, followed by automatic baseline correction and phase correction. The levels of hydroperoxides and aldehydes $\left(c_{\text {ox }}\right)$ are both expressed in $\mathrm{mmol} / \mathrm{kg}$, calculations described in Merkx et al (2018).

\section{Dynamic viscosity analysis}

Dynamic viscosity measurements at $40^{\circ} \mathrm{C}$ of the oxidized linseed biodiesel samples, precipitant and supernatant phases were performed with a Rheometer AR 2000 (TA Instruments), using a cone and plate geometry with a $4 \mathrm{~cm}$ cone in steady state flow mode. For each sample, 7 points were acquired in the range shear rate $1-100 \mathrm{~s}^{-1}$, and its average given.

\section{Peroxide Value and $p$-Ansidine Tests}

The primary oxidation products were evaluate with peroxide values (PV) tests according to the AOAC Official Method 965.33.12 (Official methods of analysis of AOAC international, 17th edn. Maryland, USA). While the p-anisidine test was used in the assessment of secondary oxidation products according to the AOCS Official Method Cd 18-90 (2002). (Barriuso et al., 2013; Symoniuk et al., 2016)

\section{GC-MS analyses}

GC analysis was conducted using a Varian 3400 apparatus (Palo Alto, CA, USA) equipped with a flame ionization detector and a Stabilwax-DA capillary column (RESTEK, Bellefonte, US; Dimension: $15 \mathrm{~m} \mathrm{x}$ $0.32 \mathrm{~mm} \times 0.25 \mu \mathrm{m})$. The oven temperature program was set to $140-230{ }^{\circ} \mathrm{C}$, with $5 \mathrm{degC} \mathrm{min}^{-1}$ increments, with a 2 and 10 min delay at the initial and final temperatures, respectively. Total run time was 30 min and carrier gas (nitrogen) pressure was approximately $70 \mathrm{kPA}$. The linseed oil samples were trans esterified to form fatty acids methyl esters (FAMEs) by alkaline-catalysis using AOCS official method Ce 2-66 (AOCS 1997). For the analyses, $20 \mu \mathrm{L}$ of the analyzed samples were dissolved in $700 \mu \mathrm{L}$ heptane, and $1 \mu \mathrm{L}$ of the supernatant was injected to the GC. Identification of peaks in the chromatogram was performed using a rapeseed FAME's mix standard purchased from Sigma-Aldrich.

Gas chromatography-mass spectrometry analyses (GC-MS) was performed using an GC-MS system SCION 
(Bruker, USA), GC-436. Detection was carried out with SQ mass-selective single quadrupole detector. The GC-MS operation control and data process were carried out by Bruker MS Workstation 8 SP2 for SCION software package.

The Varian GC capillary column part number CP7419, J\&W Select FAME GC Column, L (m) x ID (mm ) $\mathrm{x} \mathrm{OD}(\mathrm{mm}): 50 \times 0.25 \mathrm{X} 0.39$, format $7 \mathrm{inch}$, capillary tubing: fused silica, mid polarity, temperature range: $45^{\circ} \mathrm{C}-275 / 290^{\circ} \mathrm{C}$ (made in the Netherlands) was used.

The injector temperature was $280 * \mathrm{C}$. The oven temperature was held at $70 * \mathrm{C}$ for $1 \mathrm{~min}$, then increased to $270^{*} \mathrm{C}$ at heating rate $7^{*} \mathrm{C} / \mathrm{min}$. The carried gas was helium (purity $99.999 \%$ ) at flow rate $1.6 \mathrm{ml} / \mathrm{min}$. The sample volume was $1 \mu \mathrm{l}$. The conditions for election impact ionization (EI) were an ion energy of $70 \mathrm{eV}$ and mass range scanning was $39-500 \mathrm{~m} / \mathrm{z}$.

\section{Results and Discussion}

The present study was carried out as a follow up of our previous publications presenting the ${ }^{1} \mathrm{H}$ LF-NMR $2 \mathrm{D} \mathrm{T}_{1}-\mathrm{T}_{2}$ graphical maps for butter, rapeseed oil, soybean oil and linseed oil (Resende et al., 2019a,b). In these articles, we showed that the composition of the saturated/unsaturated fatty acids affects the oil's (TAG) chemical and morphological energy relaxation time domains, which could be correlated to oxidative propensity. Furthermore, we reported that using accurate $L_{1} / L_{2}$ norm regularization parameters for prima dual convex optimization (PDCO) solver for ${ }^{1} \mathrm{H}$ LF-NMR relaxation data processing (Campisi et al., 2018; 2019), could reconstruct the multi-exponential accurate $1 \mathrm{D} \mathrm{T}_{2}$ and $2 \mathrm{D}_{1} \mathrm{~T}_{1}-\mathrm{T}_{2}$ time domains of TAG and fatty acids segmental motions. This allowed the assignment of each segment's (e.g., glycerol, aliphatic chain, double bonds and tail segments) mobility in terms of $\mathrm{T}_{1}$ and $\mathrm{T}_{2}$ during the sample's thermal autoxidation (Resende et al., 2019b). The ${ }^{1} \mathrm{H}$ LF-NMR $2 \mathrm{D} \mathrm{T}_{1}-\mathrm{T}_{2}$ relaxation method was shown to be an efficient informative tool to characterize and monitor PUFA oxidation. However, as was also stated by Hwang et al. (2017) the relative long time required for $2 \mathrm{D} \mathrm{T}_{1}-\mathrm{T}_{2}$ operation is limiting its application as an on-line and also at-line in industrial production processes. In the present study, we aim to develop a rapid facile application based on selective NMR relaxometric assessment of the aliphatic tail's segmental mobility of omega-3 PUFA-rich LSO, to monitor the oil's chemical and structural changes during autoxidation.

Considering the fact with current data that in cases of relatively small molecules such as oils, $\mathrm{T}_{1}$ is almost equal to $\mathrm{T}_{2}$ (Berman et al., 2013a) and the length of time required for $\mathrm{T}_{2}$ (spin-spin) determination is very short, and it is much shorter than the time required for $\mathrm{T}_{1}$ (spin-lattice). Thus by focusing on $\mathrm{T}_{2}$ determination, shorter times of material characterization are possible. Indeed the $2 \mathrm{D} \mathrm{T}_{1}-\mathrm{T}_{2}$ is providing additional important information, especially in the final oxidation phase of termination/polymerization of LSO, characterized as a "bending effect" in which $\mathrm{T}_{2}$ is significantly decreased and $\mathrm{T}_{1}$ remains constant (Resende et al., 2019a,b). However, the fact that single $\mathrm{T}_{2}$ test provides somewhat less chemical and structural information than $2 \mathrm{D} \mathrm{T}_{1}-\mathrm{T}_{2}$ it can be compensate by multi-exponential selective assessment of the transverse relaxation time of the LSO tail as shown in Fig. 1a,b\&c, wherein increasing temperature of the LSO sample together with air $/ \mathrm{O}_{2}$ pumping and even with only temperature increase without air pumping (Berman et al., 2015, Meiri et al., 2015), shows H abstraction from the bisallylic carbons in omega-3 PUFAs, and a subsequent structural rearrangement yielding a conjugated diene can be observed, as also reported by Hwang (2015), using ${ }^{1} \mathrm{H}$ high filed NMR. Following this change a decomposition of the PUFA chain results in separation of alpha, beta unsaturated aldehydes from the original PUFA chain. This reaction is well described and documented (Vieira et al., 2017; Gorkum and Bouwman, 2005). Small fractions of low molecular weight aldehydes such as malonaldehyde (MDA) are volatized and large fractions are nonvolatile including aldehydes such as 4-hydroxy-trans-2-nonenal (HNE); 4-hydroxy-trans-2-hexanal (HHE) remains in the oxidized oil sample and interacts with other oxidation chain reaction products to form highly crosslinked polymer products (Gorkum and Bouwman, 2005). In Fig. 1a, a brief decomposition scheme is given for LSO omega-3 PUFA, consisting of 55\% linolenic acid (18:3). The chemical structure of LSO omega-3 linolenic acid and omega-9 oleic acid tail segments are marked by a red circle, and the next bisallylic segments of PUFA chains can be seen. The most common alpha, beta unsaturated aldehydes decomposed/released by products, MDA, HHE and HNE (MW= 72.06, 114.1, 156.22, respectively) have been identified in oxidized 
LSO samples by GC-MS analyses and are shown in Fig 1a.

Our group developed in the recent years a special multi-exponential computing reconstruction data processing program, based on a prima dual convex optimization (PDCO) solver for ${ }^{1} \mathrm{H}$ LF-NMR relaxometry signal inverse Laplace transformation (ILT) (Berman et al., 2013a,b; 2015; Meiri et al., 2015, Wiesman et al., 2018; Campisi et al., 2018; 2019). This novel reconstruction system has been reported as an efficient tool to distinguish between different molecular ensembles in complex systems with differential segmental motion of molecular components, and/or different morphologies (Berman et al., 2015; Meiri et al., 2016; Resende et al., 2019a,b; Campisi et al., 2018; 2019). This system's capability to differentiate the different $\mathrm{T}_{2}$ relaxation time components of LSO (glycerol, double bonds, aliphatic chains, and tails) is demonstrated for LSO (Fig 1b). It could be readily observed from the time domain (TD) peaks, that the tail segment with the highest $\mathrm{T}_{2}$ values $(818 \mathrm{~ms})$ and is the most mobile among all the LSO structural segments. In this regards it should be noted that the $\mathrm{T}_{2}$ relaxation time value of the tail includes all of the different fatty acid chains in the LSO, wherein due to its high content, the $\mathrm{T}_{2}$ relaxation time of the PUFA tails is the most mobile, with the highest values and dominates this TD peak. Using this selective segments TD system, we recently developed and demonstrated a method for selective assessment of the LSO tail $\mathrm{T}_{2}$ relaxation time (Resende et al., 2019a,b), which could determine the TD signal of tail's segmental mobility during present LSO oxidation experiments at $25,40,60,80,100,120^{\circ} \mathrm{C}$ for a time period up to $168 \mathrm{~h}$ (Fig. 1c). The data shows that the tail segment's $\mathrm{T}_{2}$ transverse relaxation time is initially $\sim 750 \mathrm{~ms}$ in all LSO tested samples. At $60^{\circ} \mathrm{C} \mathrm{T}_{2}$ relaxation times values peak $(2300 \mathrm{~ms})$ after $24 \mathrm{~h}$ and then rapidly decline until $168 \mathrm{~h}(200 \mathrm{~ms})$. At $40^{\circ} \mathrm{C}$ tail $\mathrm{T}_{2}$ peaks $(2400 \mathrm{~ms})$ after $48 \mathrm{~h}$, decline until $96 \mathrm{~h}(550 \mathrm{~ms})$ and then increase $(1500 \mathrm{~ms})$ up to $168 \mathrm{~h}$. In the control LSO sample at $25^{\circ} \mathrm{C}$ the tail $\mathrm{T}_{2}$ transverse relaxation time moderately increases and peaks after $72-96 \mathrm{~h}(1200 \mathrm{~ms})$ and then returns to its original mobility ( $\sim 50 \mathrm{~ms})$ after $120 \mathrm{~h}$ subsequently until $168 \mathrm{~h}$ it moderately increases $(1300 \mathrm{~ms})$. Though not shown in Fig. 1c (but will be further addressed later) the trend and slope of the best straight line average of tail $\mathrm{T}_{2}$ of $\mathrm{LSO}$ at $25^{\circ} \mathrm{C}$ is moderately increasing over the $168 \mathrm{~h}$ of oxidation. A similar trend is shown for LSO tail $\mathrm{T}_{2}$ at $40^{\circ} \mathrm{C}$. Both of these LSO samples $(25$ and $40^{\circ} \mathrm{C}$ ) are marked as Group A. At $60^{\circ} \mathrm{C}$ however, the trend and slope of the LSO tail $\mathrm{T}_{2}$ energy relaxation time is decreasing. This data of LSO tail $\mathrm{T}_{2}$ relaxation times suggests that in the later stages of each of the samples oxidized at $25^{\circ} \mathrm{C}$ and $40^{\circ} \mathrm{C}$ a significantly more mobile tail segment is appearing. In the case of $60^{\circ} \mathrm{C}$, however the tails' decomposition (in term of alpha, beta unsaturated aldehyde) products are more rapidly formed than in the other two lower temperatures of 40 and $25^{\circ} \mathrm{C}$. This may be rationalized that in the case of $60^{\circ} \mathrm{C}$ the very mobile TD peak after $24 \mathrm{~h}$ is associated with released tail-aldehyde and the later continuously decreased mobility is possibly due to a crosslinking with another fatty acid chain of the oxidized LSO, forming a viscous gel-like polymeric product. It should be noted that such temperature effect on increase of fatty acids $\mathrm{T}_{2}$ values was already reported and described in details (Meiri et al., 2015).

In the case of $40^{\circ} \mathrm{C}$ oxidation it is postulated that the relatively low heat energy cannot induce polymerization reactions resulting only an initial rapid increase in the tail's $\mathrm{T}_{2}$, that is explained by $\mathrm{H}$ abstraction due to introduction of heat/energy enough for decomposition of $\mathrm{H}$ bonds, followed by a continuous moderate structural rearrangement in the tail segment until the end of the experiment at $168 \mathrm{~h}$ (as supported by the study of the changes of viscosity and self-diffusion that will be presented and discussed later). In the control case of $25^{\circ} \mathrm{C}$ oxidation the kinetic rate of all the oxidation reactions are slower due to too low heat energy such that the reaction kinetics does not achieve the polymerization crosslinking phase in the frame time of the experiment. In the cases of higher oxidation temperatures $\left(80,100,120^{\circ} \mathrm{C}\right)$ marked in Fig. $1 \mathrm{c}$ as Group B, the oxidation reaction kinetics is high and the release of the decomposition aldehyde products occur already in the first few hours (until $9 \mathrm{~h}$ ). This is followed by a constant and continuous decline of the alkyl tail's $\mathrm{T}_{2}$ mobility wherein the final product is a polymeric viscous gel. In the case of the highest temperature of $120^{\circ} \mathrm{C}$, the termination phase ends after $96 \mathrm{~h}$ and the $\mathrm{T}_{2}$ value is $100 \mathrm{~ms}$. In the cases of 80 and $100^{\circ} \mathrm{C}$ the tail $\mathrm{T}_{2}$ declines up to $168 \mathrm{~h}$ to values of $120 \mathrm{~ms}$. Thus the termination phase via polymerization crosslinking forming highly viscous gel materials is characterized by low alkyl tail $\mathrm{T}_{2}$ values, representing low degrees of mobility. Therefore, it is suggested that the rate of $\mathrm{T}_{2}$ change to lower values as a function of time can be correlated with the kinetics of the aging reactions of crosslinking polymerization. 
It should be noted that in control cases that air $/ \mathrm{O}_{2}$ was not supplied or when $\mathrm{N}_{2}$ was used instead of air, to the LSO heated samples no increase of viscosity and no decrease of tail $\mathrm{T}_{2}$ values was observed even in high temperature administration (see supplemental materials 3 ). These results suggest that at the early stage of LSO autoxidation (initiation) the temperature increase is dominating the process and in more advanced stage (propagation and termination) the combination of temperature and $\mathrm{O}_{2}$ supply is controlling the process and changes of tail $\mathrm{T}_{2}$ can be explained accordingly.

The important molecular parameters in understanding the rates of the initiation, propagation and terminations phases, as monitored by $\mathrm{T}_{2}$ changes are the degree of olefin functionality and the ratio of the olefin components with the different degrees of functionality that control the onset of crosslinking polymerization and gel structure formation, and the subsequent lowering of $\mathrm{T}_{2}$ values. The linseed oil is rich in monomeric units with multifunctional double bonds (linolenic acid (18:3), and linoleic acid (18:2)). The number of monomer groups, in this case the alkyl chains of the triglycerides that must react to reach the gelation point, $p$, can be correlated to the average degree of reactive groups per monomer units in the mixture $\left(f_{\text {av }}\right)$ by $p=1 / \mathrm{f}_{\mathrm{av}}$. In the present study of linseed oil oxidation, this gel point value due to polymerization crosslinking is low because of the high content of multifunction 18:3 and 18:2. This is seen by the rapid drop in linseed oils $\mathrm{T}_{2}$ tail values because of higher crosslinking occurring at high values of reactivity of the higher temperatures compared to the lower temperatures of autoxidation (Figure 1c). This may also be readily correlated with viscosity changes as shown $n$ Figure 3. At lower temperatures, the $\mathrm{T}_{2}$ values rapidly increase due to changes in secondary interactions possibly because of alkyl chain hydrolysis without oxidative crosslinking effects. Thus in addition to covalent crosslinking affects $\mathrm{T}_{2}$ may be also influenced cohesive interactions as quantified by cohesive energy density of non-covalent interaction (e.g. polar, ionic and van der Waals forces). The strength of these secondary interactions are strongly influenced by temperature and have a corresponding effect on $\mathrm{T}_{2}$ values (Berman et al., 2015; Meiri et al., 2015).
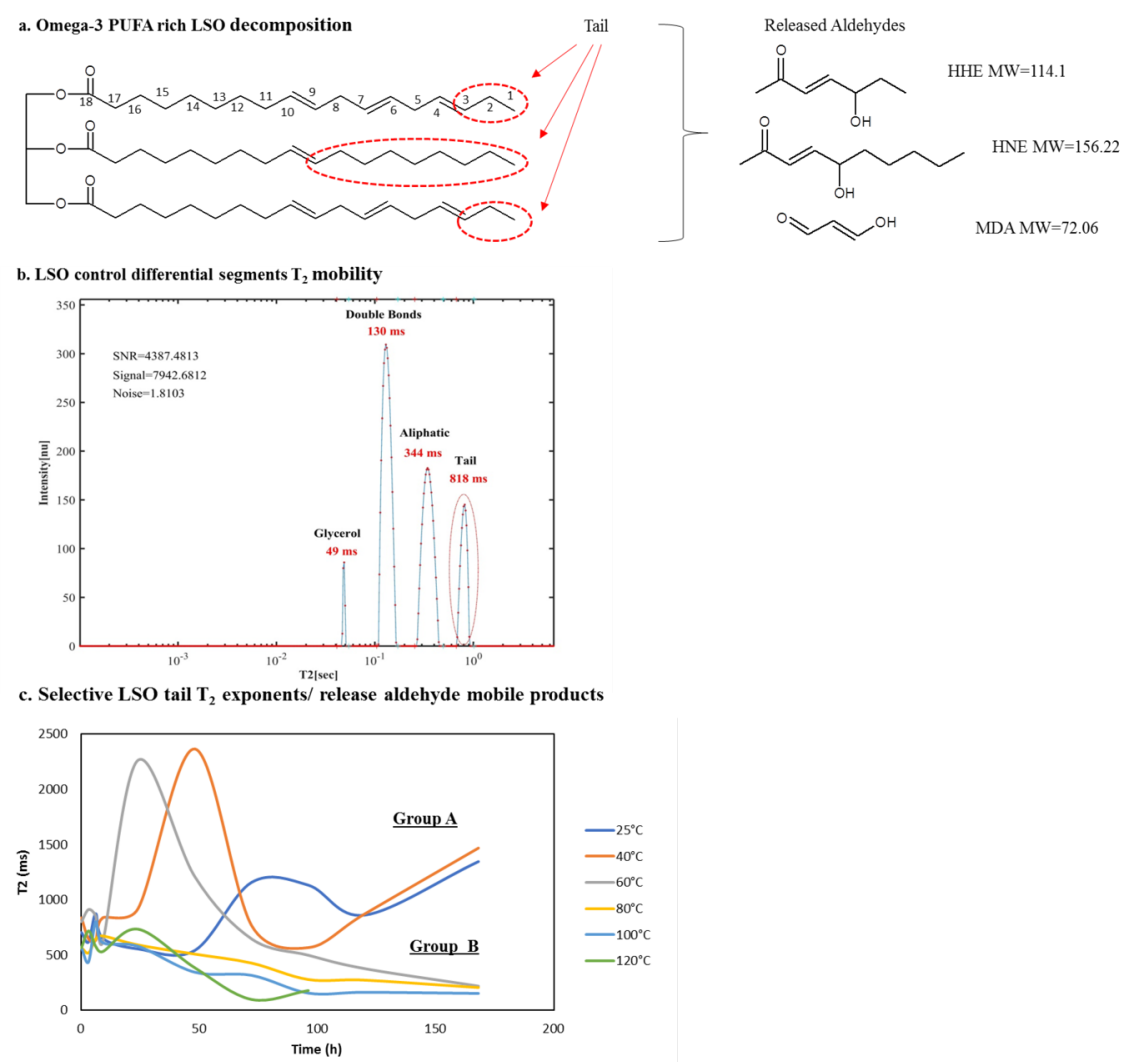
Fig. 1 Omega-3 linolenic acid-rich LSO decomposition pattern and main released aldehydes as determined by GC-MS analysis (a) selective exponents of LSO segments with emphasis of segment of tail $\mathrm{T}_{2}$ time domain relaxation determination (b) and graphic presentation of LSO tail $\mathrm{T}_{2}$ values changes during heating at 25, $40,60,80,100,120^{\circ} \mathrm{C}$ together with air pumping for 168 hours $\left(25\right.$ and $40^{\circ} \mathrm{C}$ designated as Group A and $60,80,100,120^{\circ} \mathrm{C}$ designated as Group B) (c).

Fig. 2 presents the band selective $\mathrm{HF}{ }^{1} \mathrm{H}$ NMR pulse excitation that provide quantification of hydroperoxides (Fig 2a) and aldehydes (Fig 2b) of the same LSO samples used for determining tail $\mathrm{T}_{2}$ transverse relaxation shown in Fig 1c, treated under the same thermal oxidation conditions $\left(25,40,60,80,100,120^{\circ} \mathrm{C}\right)$ with air pumping up to $168 \mathrm{~h}$. The same samples, the peroxide level of LSO at $60^{\circ} \mathrm{C}$ is the highest with a concentration peak after $96 \mathrm{~h}(380 \mathrm{mmol} / \mathrm{kg})$. Peroxide levels of LSO at $80^{\circ} \mathrm{C}$ are significantly lower than at $60^{\circ} \mathrm{C}$ and peaks after $48 \mathrm{~h}(190 \mathrm{mmol} / \mathrm{kg})$. Peroxide levels of LSO at 100 and $120^{\circ} \mathrm{C}$ are significantly lower than at $80^{\circ} \mathrm{C}$ and peak after 24 and $9 \mathrm{hrs}$, respectively. Peroxide levels at 40 and $25^{\circ} \mathrm{C}$ is minimal throughout the experiment, and reach low values of 35 and $20 \mathrm{mmol} / \mathrm{kg}$, respectively at $168 \mathrm{~h}$ (Fig. 2a). It should be noted that the peroxide level at the beginning of the experiment using stored LSO sample is about $7 \mathrm{mmol} / \mathrm{kg}$. This data is in good agreement with our PV tests of the LSO samples of the present study (not shown) and also supported by previous LSO reports (Resende et al., 2019b; Douny et al., 2016). This indicates that even at room temperatures of moderate storage condition, there are some oxidation reactions of the LSO 's PUFAs, but at a relatively low level.

Selective band HF ${ }^{1} \mathrm{H}$ NMR aldehyde analysis of LSO under thermal oxidation shows a clear temperature pattern (Figure 2b). In the LSO samples that were oxidized at 40 and $25^{\circ} \mathrm{C}$, however there was not any significant accumulation of aldehydes. From $60^{\circ} \mathrm{C}$ up to $120^{\circ} \mathrm{C}$, aldehyde levels continuously increased. In LSO samples heated at the highest temperature tested of $120^{\circ} \mathrm{C}$, aldehyde levels peak after $48 \mathrm{~h}(95$ $\mathrm{mmol} / \mathrm{kg}$ ). In LSO samples oxidized at 100,80 and $60^{\circ} \mathrm{C}$, the aldehyde levels continuously increased and did not peak after $168 \mathrm{~h}(85,60,25 \mathrm{mmol} / \mathrm{kg}$, respectively). These last data points are in agreement with the reports saying that the chain reactions of oxidation may last for relatively long time periods and the rate of these reactions depends on the environmental conditions dominated by temperature (Lazzari \& Chiantore (1999).

It is well known that due to the high speed of peroxide generation and turn over, even when using the powerful methodology of band selective ${ }^{1} \mathrm{H}$ NMR pulse excitation it is difficult to provide a detailed view of the data of peroxide levels in the very early stages of oil oxidation, in particularly for the higher thermal oxidation conditions $\left(>80^{\circ} \mathrm{C}\right)$, as shown in Fig. $2 \mathrm{~A}$.

It also should be noted that in the tail $\mathrm{T}_{2}$ TD relaxation test (Fig. 1c) a clear change of the $\mathrm{T}_{2}$ could be observed at 60,40 and $25{ }^{\circ} \mathrm{C}$ after $24,48 \mathrm{~h}$ and $72 \mathrm{~h}$, respectively. However even in the case of the selective tail T2 methodology results, it is difficult to view a clear and detailed pattern of changes in the very early phase of the first 10 hours of the oxidation process.

To further and better study and verify the changes of chemical composition, GC-MS analysis of all the LSO samples used in the present study was carried out. Table 1 presents the changes of the non-oxidized saturated (SAT), monounsaturated (MUFA) and polyunsaturated (PUFA) fatty acids during LSO thermal autoxidation $\left(25,40,60,80,100,120^{\circ} \mathrm{C}\right)$ for $0,3,6,9,24,48,72,96,120,168 \mathrm{~h}$. At low temperatures of 25 and $40^{\circ} \mathrm{C}$ the profile of the three groups of fatty acids seem to be stable, while the profile of $60^{\circ} \mathrm{C}$ demonstrate significant decrease/loss of PUFA at the later time periods (120 and $168 \mathrm{~h})$ and relative increase in MUFA and SAT. At $80^{\circ} \mathrm{C}$ there is a moderate decrease of PUFA and an increase of MUFA and SAT after $48 \mathrm{up}$ to $168 \mathrm{~h}$. At the higher temperatures of 100 and $120^{\circ} \mathrm{C}$ a similar pattern is observed, but with a faster rate of PUFA loss starting from $24 \mathrm{~h}$ up to $120 \mathrm{~h}$ and $96 \mathrm{~h}$, respectively, in which the original liquid sample is transformed to a viscous gel. 

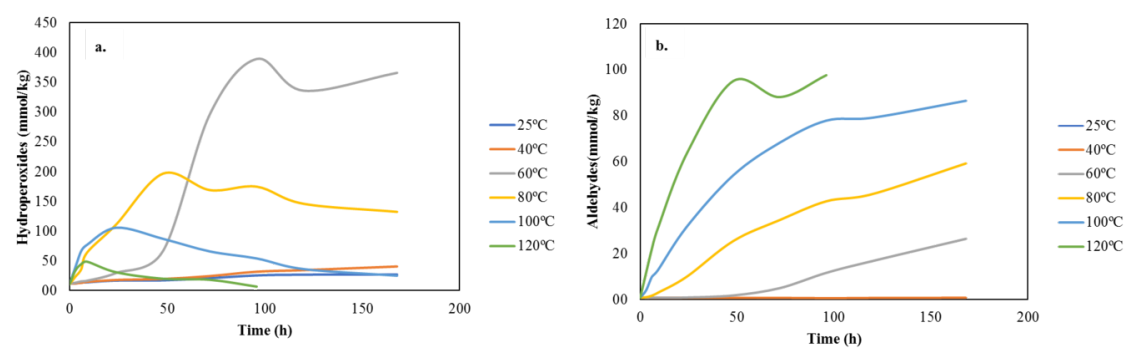

Fig. 2 Selective band NMR determination of hydroperoxides (a) and aldehydes (b) at 25, 40, 60, 80, 100, $120^{\circ} \mathrm{C}$ for $168 \mathrm{~h}$.

Table 1 Changes of LSO profile of fatty acids during thermal oxidation, as determined by GC-M (SATsaturated; MUFA- mono-unsaturated fatty acids; PUFA- polyunsaturated fatty acids)

\begin{tabular}{lllllllllllll}
\hline T-168 & T-120 & T-120 & T-96 & T-72 & T-48 & T-24 & T-9 & T-6 & T-3 & T-0 & FA & Temp' \\
\hline 7.45 & 7.45 & 6.70 & 6.92 & 6.35 & 7.12 & 6.86 & 6.60 & 6.71 & 7.26 & 7.05 & SAT & $25^{\circ} \mathrm{C}$ \\
26.71 & 26.71 & 27.39 & 27.63 & 28.24 & 28.11 & 27.86 & 28.09 & 28.36 & 28.00 & 28.42 & MUFA & \\
65.84 & 65.84 & 65.91 & 65.45 & 65.41 & 64.77 & 65.26 & 65.31 & 64.93 & 64.74 & 64.53 & PUFA & \\
6.79 & 6.79 & 7.62 & 9.04 & 6.93 & 9.10 & 7.62 & 8.00 & 7.30 & 7.42 & 7.12 & SAT & $40^{\circ} \mathrm{C}$ \\
29.14 & 29.14 & 28.60 & 29.37 & 29.23 & 28.04 & 27.22 & 27.43 & 27.17 & 28.20 & 28.14 & MUFA & \\
64.07 & 64.07 & 63.78 & 61.59 & 63.84 & 62.86 & 65.16 & 64.57 & 65.53 & 64.38 & 64.74 & PUFA & \\
13.06 & 13.06 & 9.61 & 6.99 & 8.11 & 7.29 & 6.83 & 6.61 & 7.05 & 6.81 & 7.16 & SAT & $60^{\circ} \mathrm{C}$ \\
47.20 & 47.20 & 42.36 & 35.40 & 33.17 & 29.33 & 28.69 & 29.18 & 28.65 & 29.23 & 28.10 & MUFA & \\
39.74 & 39.74 & 48.03 & 57.61 & 58.72 & 63.38 & 64.48 & 64.21 & 64.30 & 63.96 & 64.74 & PUFA & \\
11.37 & 11.37 & 10.49 & 9.15 & 8.01 & 8.43 & 8.33 & 8.06 & 8.22 & 7.10 & 7.41 & SAT & $80^{\circ} \mathrm{C}$ \\
40.19 & 40.19 & 37.06 & 35.41 & 32.12 & 32.21 & 29.30 & 29.15 & 28.12 & 28.03 & 28.50 & MUFA & \\
48.44 & 48.44 & 52.45 & 55.44 & 59.87 & 59.36 & 62.37 & 62.79 & 63.66 & 64.87 & 64.09 & PUFA & \\
& & 13.41 & 16.12 & 8.59 & 8.34 & 8.01 & 8.10 & 7.17 & 7.03 & 7.28 & SAT & $100^{\circ} \mathrm{C}$ \\
& & 41.12 & 38.47 & 38.36 & 34.45 & 31.20 & 30.42 & 29.11 & 28.09 & 28.31 & MUFA & \\
& & 45.47 & 45.41 & 53.05 & 57.21 & 60.79 & 61.48 & 63.72 & 64.88 & 64.41 & PUFA & \\
& & & 15.67 & 21.29 & 19.43 & 9.04 & 9.41 & 8.23 & 10.32 & 7.15 & SAT & $120^{\circ} \mathrm{C}$ \\
& & & 46.52 & 4040.21 & 38.42 & 33.00 & 28.62 & 29.19 & 28.09 & 28.20 & MUFA & \\
\hline
\end{tabular}

The mechanistic pattern of LSO oxidation can be seen in the viscosity measurements of all the samples described in Fig. 3, at different oxidative temperatures and time. The two lowest temperature samples (25 and $40^{\circ} \mathrm{C}$ ) marked as Group A show a minimal or no heating effect and remain at a low constant viscosity over all the time tested from time 0 up to 168 hours. The LSO samples treated with higher temperatures from $60^{\circ} \mathrm{C}$ up to $120^{\circ} \mathrm{C}$ marked as Group B, clearly show an increase of viscosity over time, however it is possible to differentiate between each temperature. There is a period of very minimal "heating effect" of $96,72,48$ and 24 hours for $60,80,100$ and $120^{\circ} \mathrm{C}$, respectively. Following this early phase there is a dramatic increase of level of viscosity of the samples closely dependent of the temperature. It is interesting to note that non of the samples reach a peak point and may further increase if the experiment might be extended. The viscosity of the LSO sample treated with air pumping and heated to $120^{\circ} \mathrm{C}$, reached to a maximal level of viscosity (0.8 Pa.s) and lost its fluidity already after 72 hours. The sample treated with $100^{\circ} \mathrm{C}$ reached also a similar level of viscosity after 120 Hours and the other two samples of Group B reach a level of viscosity of 0.4 Pa.s at the end of the experiment. The fact that all the samples treated with air and increase temperature $\left(>60^{\circ} \mathrm{C}\right)$ reached a point of viscous gel-like products suggest of a significant 
temperature depended polymerization phase, as the termination step of the autoxidation process. These results are in agreement with the literature reported on termination phase of LSO oxidation (Douny et al., 2016; Vieira et al., 2017; Resende et al., 2019).

The fact that in all cases there was a "leg time" or a "induction period" that it length is depended of the temperature level may suggest that a certain level of energy introduction to the sample is required to release the weak interactions kept by van der Waals and hydrogen bonds (H abstraction) in the original liquid LSO, so that oxygen from the pumped air may be able to interact with the rearranged conjugated diene segments of the PUFAs of the LSO. In other words, the heating "induction period" open and stimulates the autoxidation process of LSO by making some delicate structural changes. The ability to monitor these changes may open the way to evaluate the progress of the oxidation of LSO from relatively early stages until the termination phase. Based on previous publications (Berman et al., 2015, Meiri et al., 2015) discussing the relationship between ${ }^{1} \mathrm{H}$ NMR $\mathrm{T}_{2}$ and weak forces effects on fatty acids structure and assembly in different temperatures, we suggest that LSO tail $\mathrm{T}_{2}$ changes during the period of minimal "heating effect" described above (Fig. 1c) are providing good information required for evaluation of the chemical and structural changes during LSO autoxidation. Furthermore, correlation of tail $\mathrm{T}_{2}$ vs. viscosity show that only after several testing time points (depending of heating temperature) both parameters well correlate (see supplemental information 2).

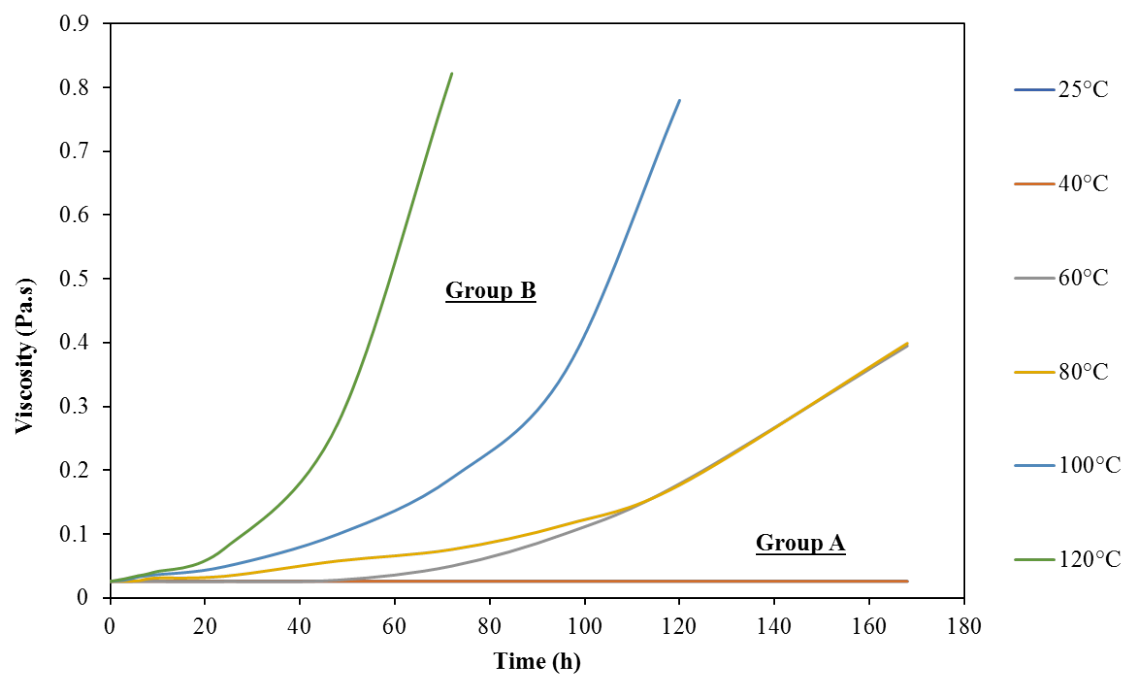

Fig. 3 Changes of LSO viscosity as a function of temperature $\left(25,40,60,80,100,120^{\circ} \mathrm{C}\right)$ over a time span of $168 \mathrm{~h}$. ( 25 and $40^{\circ} \mathrm{C}$ designated as Group A and $60,80,100,120^{\circ} \mathrm{C}$ designated as Group B).

Using the GC-MS data collected regarding the changes of LSO non-oxidized saturated fatty acids (SAFA), monounsaturated fatty acids (MUFA) and polyunsaturated fatty acids (PUFA) (Table 1) and data for two LSO oxidized products, hydroperoxides and aldehydes (Fig. 2), we made a semi-quantified estimation of the changes of the level of polymers/epoxides during the 168 hours of LSO autoxidation (see details and graphic description for all temperatures in Supplemental material 4). This estimation demonstrates that when LSO samples were heated to $25^{\circ} \mathrm{C}$ and $40^{\circ} \mathrm{C}$ together with continuous air supply, no significant polymers/epoxides products could be observed above threshold of $10 \%$ all over the time frame of the experiment. In LSO samples heated to $60^{\circ} \mathrm{C}$ and higher temperatures plus air pumping the level of polymers/epoxides significantly increased above the threshold to $28,27,41$ and $50 \%$, respectively for $60,80,100,120^{\circ} \mathrm{C}$ at the end time of 168 hours

NMR self-diffusion (D) experiments of the same LSO samples during thermal oxidation at increasing temperatures $\left(25,40,60,80,100,120^{\circ} \mathrm{C}\right)(\mathrm{Fig}$. 4). The self -diffusion results suggest two autoxidation reaction rates as a function of temperature. One group consists of LSO autoxidation at low temperatures (25 and 
$40^{\circ} \mathrm{C}$ ) that may relate to a slow rate of oxidation (Slow Ox). The second group of LSO treated at higher oxidative temperatures $\left(80,100,120^{\circ} \mathrm{C}\right)$ resulting in rapid oxidation rates Rapid $\left.\mathrm{Ox}\right)$. Furthermore, the self-diffusion analysis may also suggest an intermediate oxidation mechanism at $60^{\circ} \mathrm{C}$, which may be the intermediate temperature point in going from slow to rapid autoxidation of LSO.

It should be noted that viscosity values change only several hours in a limited scale of 0.05 to 0.8 Pa.s in between Group A and Group B depending of heating temperature. This data corresponds with the findings described and explained above for the induction period of LSO oxidation.

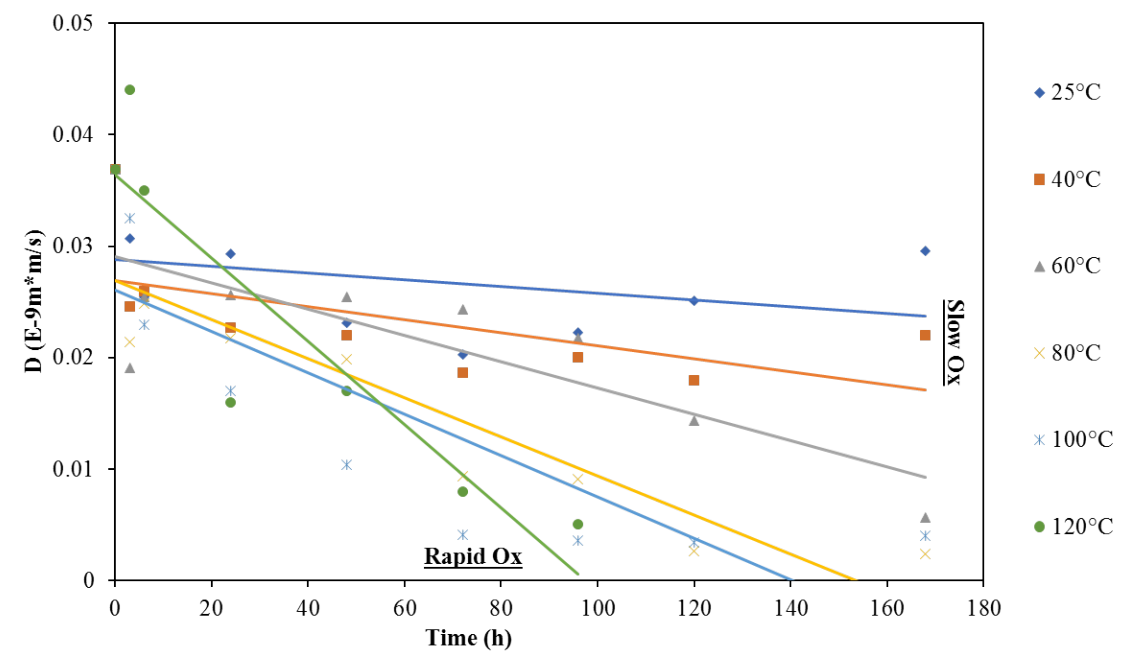

Fig. 4 Changes of LSO self-diffusion (D) trend at $25,40,60,80,100,120^{\circ} \mathrm{C}$ during $168 \mathrm{~h}$. (25 and $40 \mathrm{oC}$ designated as Slow $\mathrm{Ox}$, and $6080,100,120^{\circ} \mathrm{C}$ designated as Rapid Ox)

The D values in Fig. 4, at different times of LSO oxidation were correlated in Fig 5 to the ${ }^{1} \mathrm{H}$ LF-NMR $\mathrm{T}_{2}$ mobility values of the LSO omega-3 PUFA-rich tail end of the alkyl chains. As can be seen in Fig. 5, there is a good correlation between the $\mathrm{D}$ and $\mathrm{T}_{2}$ values. Again the two main autoxidation mechanisms can be observed. One mechanism at low temperatures of oxidation is characterized by negative slope over the $168 \mathrm{~h}$ of oxidation, due to a slow oxidation rate of LSO. The second oxidation mechanism at higher temperatures is characterized by a positive slope for $168 \mathrm{~h}$, due to a rapid oxidation rate of LSO. The temperature of $60^{\circ} \mathrm{C}$ also shows a positive slope, but more moderate than at higher temperatures. This last result supported with correlation of self-diffusion vs. viscosity (supplemental information 1) and $\mathrm{T}_{2}$ vs. viscosity (supplemental information 2) further confirms that $60^{\circ} \mathrm{C}$ is the temperature point for initiating a rapid LSO oxidation and aging. 


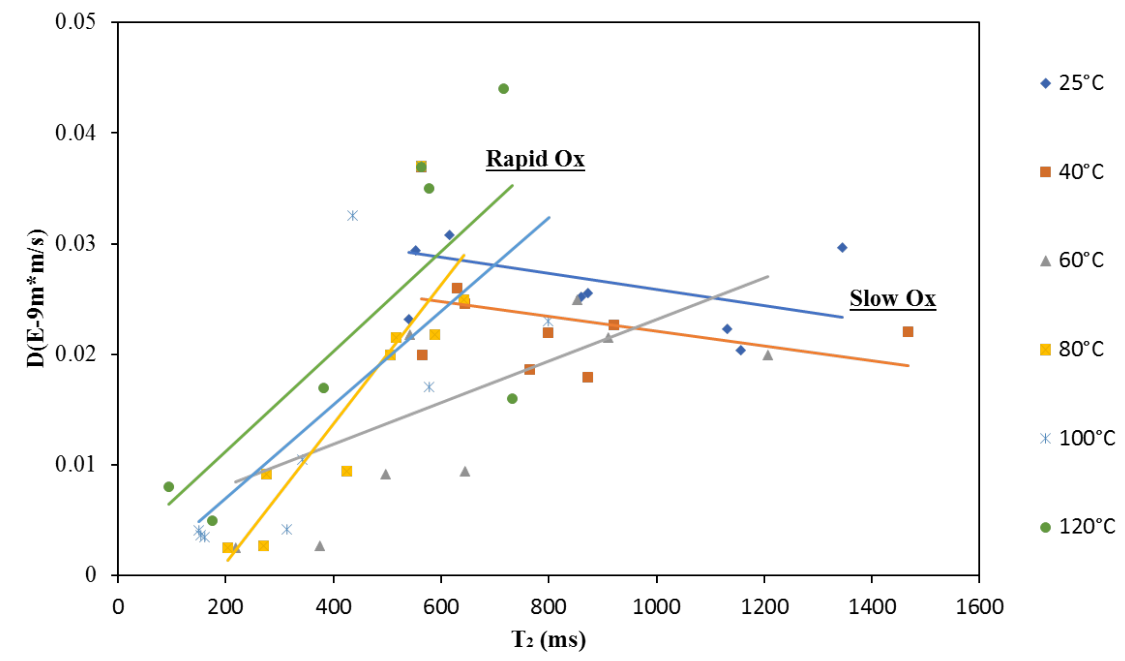

Fig. 5 Correlation between LSO self-diffusion and Tail $\mathrm{T}_{2}$ at $25,40,60,80,100,120^{\circ} \mathrm{C}$ during $168 \mathrm{~h}$. (25 and $40^{\circ} \mathrm{C}$ designated as Slow $\mathrm{Ox}$ and $60,80,100,120^{\circ} \mathrm{C}$ designated as Rapid Ox)

In summary we have shown that the $\mathrm{T}_{2}$ (spin-spin) transversal relaxation time of the alkyl chain tail reflects the chemical and structural changes occurring during LSO aging via a thermal autoxidation process. In effect, $\mathrm{T}_{2}$ can be correlated to the kinetics of oxidation as influenced by the temperature, and can be correlated as we show, to chemical changes such as covalent crosslinking polymerization, and peroxide and aldehyde formation and changes in component concentrations such as PUFA, MUFA and SAT) and different material properties such as viscosity and diffusivity.

\section{Conclusions}

The above study demonstrates the efficacy of $\mathrm{T}_{2}$ (spin-spin) transversal relaxation time of the alkyl chain tail to follow the chemical and structural changes occurring during LSO aging via a thermal autoxidation process over a temperature of 25 to $120 \mathrm{C}$. For example aliphatic chains tail's $\mathrm{T}_{2}$ energy relaxation TD of LSO samples heated and exposed to air's $\mathrm{O}_{2}$ up to $40^{\circ} \mathrm{C}$ clearly correlates with an increase rate of peroxides production that is not immediately followed with a significant rate of aldehydes accumulation, nor crosslinking polymerization. Heating of LSO at $60^{\circ} \mathrm{C}$, however shows that this is the turning point in which the oxidation process is completed by forming aldehydes and terminates with polymerization products. As heating temperatures are increased the rate of LSO oxidation increase dramatically.

The above results demonstrate that ${ }^{1} \mathrm{H}$ LF-NMR $\mathrm{T}_{2}$ transversal energy relaxation times of the PUFA's terminal alkyl chain can be used to readily, with at-line facile instruments, to determine the different stages of LSO oxidation, beyond what is currently available. The $\mathrm{T}_{2}$ relaxation time values in the early stages of oxidation change from the non-oxidized samples as a function of the temperature of autoxidation. At the lowest reported temperatures of autoxidation $\left(25^{\circ} \mathrm{C}\right.$ and $\left.40^{\circ} \mathrm{C}\right)$ an initiation and propagation phase of oxidation result, without the termination phase, giving molecular structures, as graphically shown, with the lowest viscosities and higher $T_{2}$ values due to increased chain mobility because of chain decomposition. At higher temperatures of LSO oxidation, starting at $60^{\circ} \mathrm{C}$ there are the stages of initiation, propagation and termination of oxidation wherein the latter is the formation of polymerization phases with high viscosity. Thus with increasing temperature above $60^{\circ} \mathrm{C}\left(80,100\right.$ and $\left.120^{\circ} \mathrm{C}\right)$ a rapid polymerization process results in significantly lower $\mathrm{T}_{2}$ relaxation times due to increase of viscosity. Hydroperoxides are rapidly converted to other products such as aldehydes and polymers. Polymerization is reflected in changes in the $\mathrm{T}_{2}$ relaxation times of alkyl chains, higher viscosities and lower self-diffusion constants. Thus this rapid polymerization process at higher oxidation temperatures results in significantly lower $\mathrm{T}_{2}$ at a material stage that has lower peroxide values than found at lower oxidation temperatures. 
These lower temperatures of oxidation have a $T_{2}$ peaking over time that is postulated to represents increasing mobility because of chain decomposition and then a relatively slow decrease in $\mathrm{T}_{2}$ values possibly due to increased molecular crosslinking and appearance of viscous gel-like product.

These results show the versatility of selective $\mathrm{T}_{2}$ relaxation time assessment of LSO's rich in alkyl chain of omega-3 PUFA and most likely in other oils, to readily determine the state of oxidation. Therefore, it is postulated that selective determination of LSO tail $\mathrm{T}_{2}$ relaxation times can be used as a facile and accurate marker of the omega-3 PUFA-rich oil oxidative aging process.

Acknowledgments The authors would like to acknowledge Prof. John van Duynhoven and Mr. Donny Merkx from Wageningen University for their support with HR NMR study and valuable comments and suggestions. We also would like to thank Dr. Z. Abramovich for the technical work with GC, Mrs. Shoshana Kravchik and all the members of PLBL for general laboratory assistance. This study was partially supported by a grant from Ministry of Science and Technology, Israel.

\section{References:}

Bakota, E. L , Winkler-Moser, J.K., \& Palmquist, D. E. (2012) Solid fat content as a substitute for total polar compound analysis in edible oils. Journal of the American Oil Chemists' Society, 89 (12):2135-2142.

Barriuso, B., Astiasarn, I., \& Ansorena, D. (2013) Measuring lipid oxidation status in foods: A challenging task. European Food Research and Technology , 236 :1-15.

Berman, P., Leshem, A., Etziony, O., Levi, O., Parmet, Y., Saunders, M., \& Wiesman, Z. (2013a) Novel 1 $\mathrm{H}$ low field nuclear magnetic resonance applications for the field of biodiesel. Biotechnology for Biofuels , 6 :55-75.

Berman, P., Levi, O., Parmet, Y., Saunders, M., \& Wiesman, Z. (2013b) Laplace inversion of low-resolution NMR relaxometry data using sparse representation methods. Concepts in Magnetic Resonance Part A ,42 :72-88.

Berman, P., Meiri, N., Colnago, L. A., Morales, T. B., Linder, C., Levi, O., ... Wiesman, Z. (2015) Study of liquid-phase molecular packing interactions and morphology of fatty acid methyl esters (biodiesel). Biotechnology for Biofuels , 8 :12-28.

Berman, P., Meiri, N., Linder, C., \& Wiesman, Z. (2016) $)^{1} \mathrm{H}$ low field nuclear magnetic resonance relaxometry for probing biodiesel autoxidation. Fuel , $177: 315-325$.

\section{Blumich, B. (2016) Introduction to compact NMR: A review of methods. Trends in Analytical Chemistry, 83:2-11}

Budilarto, E. S., \& Kamal-Eldin, A. (2015) The supramolecular chemistry of lipid oxidation and antioxidation in bulk oils. European Journal of Lipid Science and Technology, 117 :1095-1137.

Campisi-Pinto, S., Levi, O., Benson, D., Cohen, M., Resende, M. T., Saunders, M., \& Wiesman, Z. (2018) Optimal regularization parameters of primal-dual interior method for convex objectives (PDCO) applied to 1H low field nuclear magnetic resonance (1H LF-NMR). Applied Magnetic Resonance , 49 :1129-1150.

Campisi-Pinto, S., Levi, L., Benson, D., Resende, M. T., Saunders, M., Linder, C., \& Wiesman, Z. (2019) Simulation-Based Sensitivity Analysis of Regularization Parameters for Robust Reconstruction of Complex Material's T1 - T21H LF-NMR Energy Relaxation Signals. Applied Magnetic Resonance , 1-18.

Carr, H. Y., \& Purcell, E. M. (1954) Effects of diffusion on free precession in nuclear magnetic resonance experiments. Physical Review, 94 :630-638. 
Douny, C., Razanakolona, R., Ribonnet, L., Milet, J., Baeten, V., Rogez, H., Scippo, M. L., \& Larondelle, Y. (2016) Linseed oil presents different patterns of oxidation in real-time and accelerated aging assays. Food Chemistry, 208 : 111-115

Graham, J.W., Hofer, S.M. \& MacKinnon, D.P. (1996). Maximizing the usefulness of data obtained with planned missing value patterns: An application of maximum likelihood procedures. Multivariate Behavorial Research , 31, 197-218.

Gorkum, R., \& Bouwman, E. (2005) The oxidative drying alkyd paint catalyzed by metal complexes. Coordination Chemistry Reviews, 249 :1709-1728.

Gouilleux, B., Charrier, B., Akoka, S., Felpin, F-X., Rodriguez-Zubiri, M., \& Giraudeau, P. (2016) Ultrafast 2D NMR on a benchtop spectrometer: Applications andperspectives. Trends in Analytical Chemistry ,83 : $65-75$

Guillén, M. D., \& Uriarte, P. S. (2009) Contribution to further understanding of the evolution of sunflower oil submitted to frying temperature in a domestic fryer: study by $1 \mathrm{H}$ nuclear magnetic resonance. Journal of Agricultural and Food Chemistry, 57 (17):7790-7799.

Hein, M., Henning, H., \& Isengard, H. D. (1998) Determination of total polar parts with new methods for the quality survey of frying fats and oils. Talanta, 47 (2):447-454.

Hwang, H S. (2015) NMR spectroscopy for assessing lipid oxidation.Lipid Technology, 27 (8):187-189.

Hwang, H. S., Winkler-Moser, J. K. \& Liu, S. (2017) Reliability of 1H NMR Analysis for Assessment of Lipid Oxidation at Frying Temperatures. Journal of the American Oil Chemists' Society,94: 257-270.

Juita, Dlugogorski, B. Z., Kennedy, E. M., \& Mackie, J. C. (2013) Roles of peroxides and unsaturation in spontaneous heating of linseed oil.Fire Safety Journal , 61 :108-115.

Kaleem, A., Aziz, S.,Iqtedar, M.,Abdullah, R.,Aftab, M., Rashid, F., Shakoori, F. R. , Naz, S. (2015) Investigating changes and effect of peroxide values in cooking oils subject to light and heat. FUAST Journal of Biology , 5 (2): 191-196.

Lazzari, M., \& Chiantore, O. (1999) Drying and Oxidative Degradation of Linseed Oils. Polymer Degradation and Stability, 65 :303-313.

Jacobsen, C. (2015) Some strategies for the stabilization of long chain n-3 PUFA-enriched foods: A review, European Journal of Lipid Science and Technology 2015, 117 :1853-1866.

Meiboom, S., \& Gill, D. (1958) Modified spin-echo method for measuring nuclear relaxation times. Review of Scientific Instruments ,29:688-691.

Meiri, N., Berman, P., Colnago, L. A., Moraes, T. B., Linder, C., \& Wiesman, Z. (2015) Liquid phase characterization of molecular interactions in polyunsaturated and n-fatty acid methyl esters by $1 \mathrm{H}$ low field nuclear magnetic resonance. Biotechnology for Biofuels ,8:96-108.

Merkx, D. W. H., Hong, G. T. S., Ermacora, A., \& van Duynhoven, J. P. M. (2018) Rapid Quantitative Profiling of Lipid Oxidation Products in a Food Emulsion by 1H NMR. Analytical Chemistry, 90 : 48634870.

Resende, M. T., Campisi-Pinto, S., Linder, C., \& Wiesman, Z. (2019) Multidimensional Proton Nuclear Magnetic Resonance Relaxation Morphological and Chemical Spectrum Graphics for Monitoring and Characterization of Polyunsaturated Fatty-Acid Oxidation. Journal of the American Oil Chemists' Society, 96 :125-135.

Resende, M. T., Linder, C., \& Wiesman, Z. (2019) ${ }^{1}$ H LF-NMR Energy Relaxation Time Characterization of the Chemical and Morphological Structure of PUFA-Rich Linseed Oil During Oxidation With and Without Antioxidants. European Journal of Lipid Science and Technology , 121 : 1800339-1800347. 
Rudszuck, T., Foster, E., Nirschl, H. , \& Guthausen, G. (2019) Low-field NMR for quality control in Oils. Magnetic Resonance in Chemistry, 57 : 777-793.

Stejskal, E. O., \& Tanner, J. E. (1965) Spin Diffusion Measurements: Spin Echoes in the Presence of a Time-Dependent Field Gradient. The Journal of Chemical Physics , 42:288-292.

Symoniuk, E., Ratusz, K., \& Krygier, K. (2016) Comparison of the oxidative stability of linseed (Linum usitatissimum L.) oil by pressure differential scanning calorimetry and Rancimat measurements. Journal of Food Science and Techno logy,53 : 3986-3995.

Song, Y., Venkataramanan, L., Hurlimann, M. D., Flaum, M., Frulla, P., \& Straley, C. (2002) T1-T2 correlation spectra obtained using a fast two-dimensional Laplace inversion. Journal of Magnetic Resonance ,154:261-268.

Sun, X.,\& Moreira, R. G. (1996) Correlation between NMR proton relaxation time and free fatty acids and total polar materials of degraded soybean oils. Journal of Food Processing and Preservation, 20 (2):157-167.

Sun, Y-E., Wang, W-D., Chen, H-W., \& Li, C. (2011) Autoxidation of unsaturated lipids in food emulsion. Journal Critical Reviews in Food Science and Nutrition, 51 (5):453-466.

Wiesman, Z., Linder, C., Resende, M. T., Ayalon, N., Levi, O., Bernardinelli, O. D., Jackman, R. (2018) 2D and 3D Spectrum graphics of the chemical-morphological domains of complex biomass by low field proton NMR energy relaxation signal analysis. Energy \& Fuels ,32:5090-5102.

Velasco, J., Andersen, M. L., \& Skibsted, L. H. (2005) Electron Spin Resonance Spin Trapping for Analysis of Lipid Oxidation in Oils: Inhibiting Effect of the Spin Trap r-Phenyl-N-tert-butylnitrone on Lipid Oxidation. Journal of Agricultural and Food Chemistry ,53 :1328-1336.

Vieira, S. A., Zhang, G., \& Decker, E. A. (2017) Biological implications of lipid oxidation products. Journal of the American Oil Chemists' Society, $94,339-351$.

Zhang, Q., Saleh, A. S., Chen J, \& Shen, Q. (2012) Chemical alteration taken place during deep-frying based on certain reaction products: a review. Chemistry and Physics of Lipids, 165 :662-681.

\section{Supplemental information:}

1. Supplemental material - Self-diffusion versus viscosity

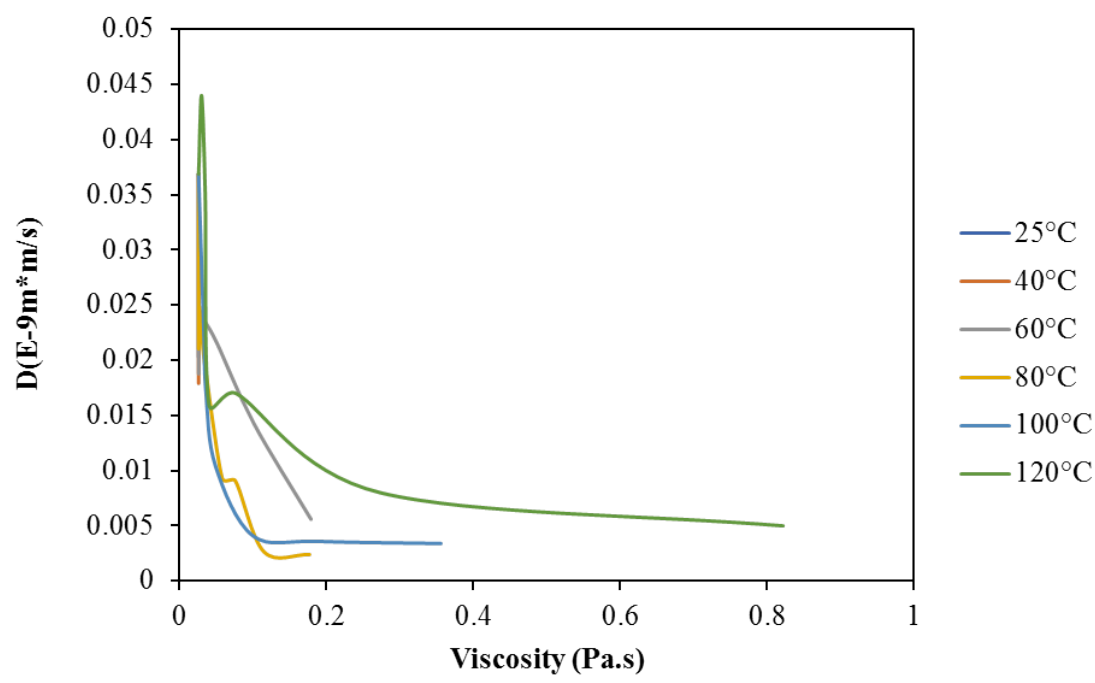



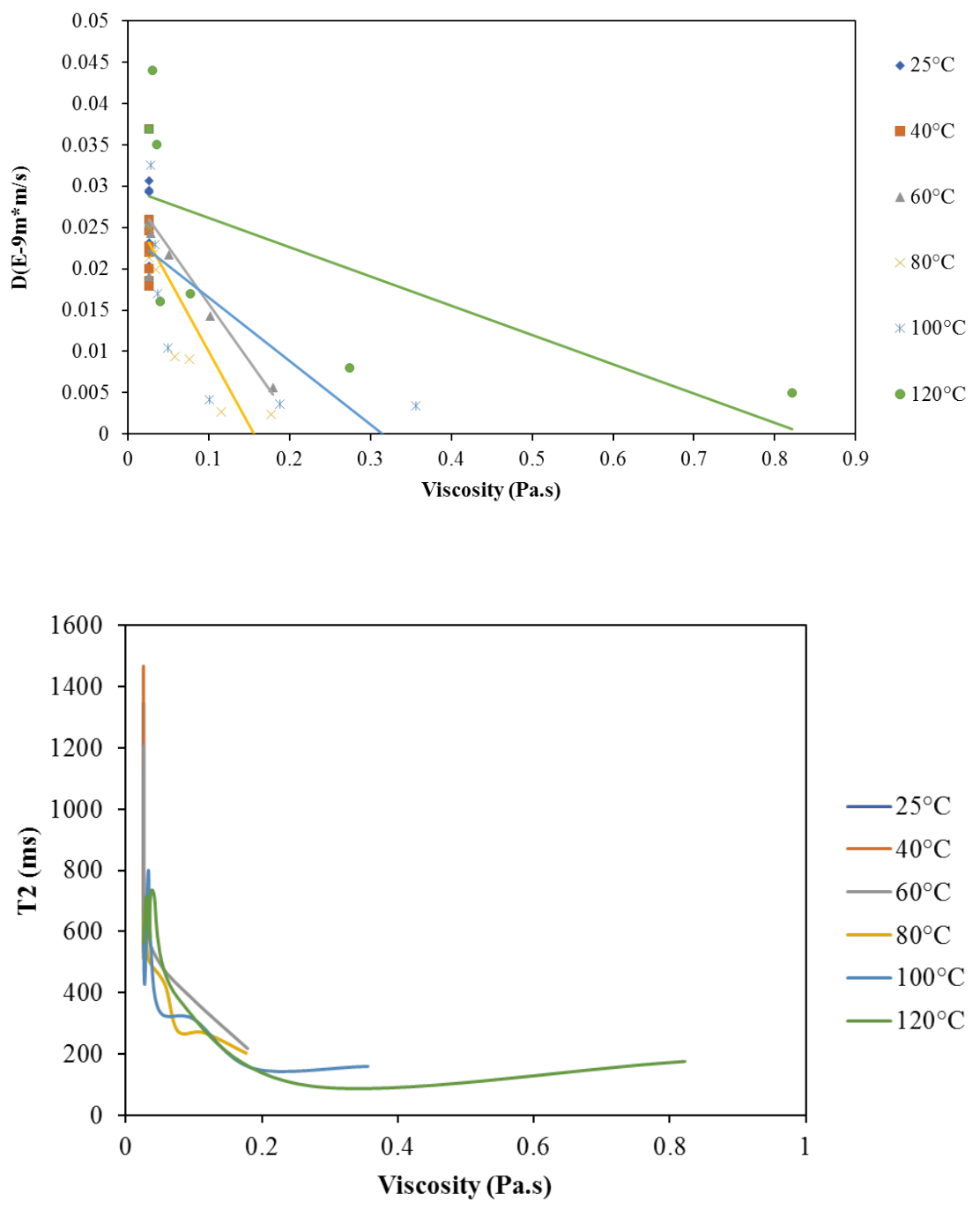

2. Supplemental material - Tail $\mathrm{T}_{2}$ versus viscosity 


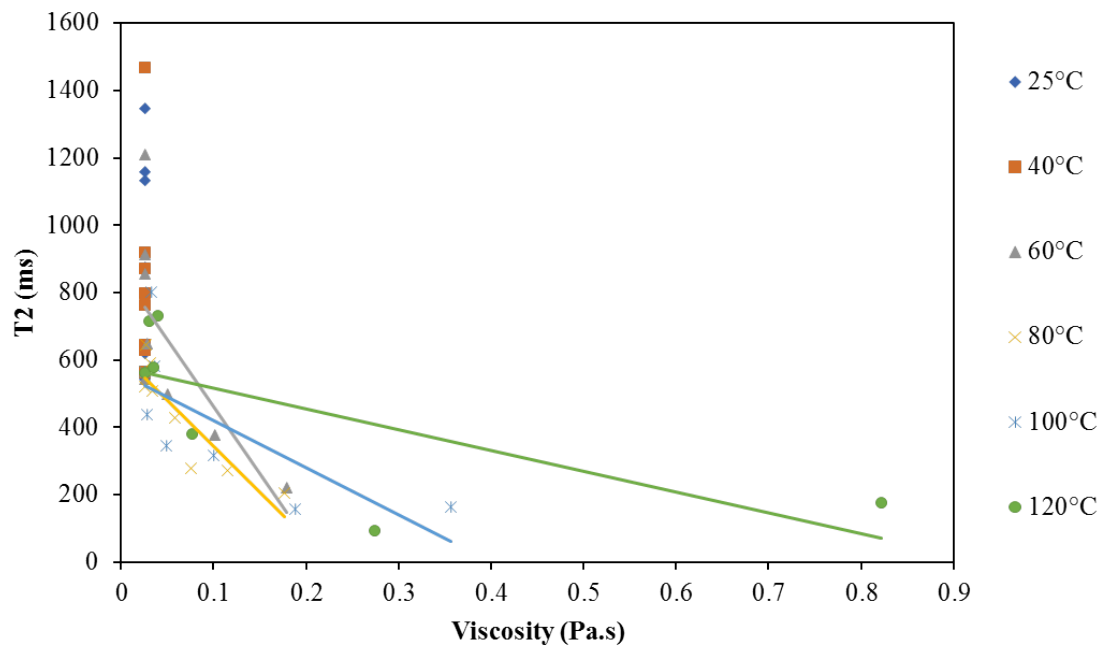

3. Supplemental material - Control of LSO heated with and without air/O2 supply.

Tail $\mathbf{T}_{2}(\mathrm{~ms})$

Testing time(hours) T-0 T-24 T-48 T-72 T-96 T-120 T-168

Treatment_

LSO-25 ${ }^{\circ} \mathrm{C}-$ No Air pumped 783750703718703 nd nd

LSO- $25^{\circ} \mathrm{C}+\mathrm{N} 2$ pumped 766673750800658703 nd

LSO-25 ${ }^{\circ} \mathrm{C}+$ Air pumped 750710685120011058901300

LSO-40 ${ }^{\circ} \mathrm{C}+$ Air pumped 75089024007407508801400

LSO-60 ${ }^{\circ} \mathrm{C}+$ Air pumped 75023001100730660410200

LSO-80 ${ }^{\circ} \mathrm{C}+$ Air pumped 750680550490300300200

LSO-100 ${ }^{\circ} \mathrm{C}+$ Air pumped 750690410470150140120

LSO- $120^{\circ} \mathrm{C}+$ Air pumped 750870500120160 nd nd

4. Supplemental material - Estimation of polymers/epoxides levels in heated LSO samples

[CHART]

\begin{tabular}{lllllllllll}
\hline & 0 & 0 & 3 & 6 & 9 & 24 & 48 & 72 & 96 & 1 \\
\hline SAFA & SAFA & 7.05 & 7.05 & 7.05 & 7.05 & 7.05 & 7.05 & 7.05 & 7.05 & 7 \\
UFA (nonOx) & UFA (nonOx) & 93.0 & 90.1 & 98.0 & 99.8 & 95.7 & 92.0 & 104.0 & 94.8 & 9 \\
PeroxAld & PeroxAld & 0.58308 & 0.585167 & 0.638602 & 0.65836 & 0.786938 & 0.802117 & 0.964065 & 1.166085 & 1 \\
PolymEpox & PolymEpox & 0 & 2.890475 & -5.12259 & -6.89346 & -2.95298 & 0.764108 & -11.4046 & -2.46162 & - \\
\hline
\end{tabular}

[CHART]

\begin{tabular}{lllllllllll}
\hline & 0 & 3 & 6 & 9 & 24 & 48 & 72 & 96 & 120 & 168 \\
\hline SAFA & 7.41 & 7.41 & 7.41 & 7.41 & 7.41 & 7.41 & 7.41 & 7.41 & 7.41 & 7.41
\end{tabular}




\begin{tabular}{lllllllllll}
\hline & 0 & 3 & 6 & 9 & 24 & 48 & 72 & 96 & 120 & 168 \\
\hline UFA (nonOx) & 92.6 & 97.0 & 82.7 & 84.5 & 81.5 & 80.5 & 85.1 & 73.6 & 63.2 & 57.8 \\
PeroxAld & 0.519961 & 1.08836 & 1.678084 & 2.97248 & 5.37743 & 9.835649 & 9.010141 & 9.627194 & 8.497498 & 8.4855 \\
PolymEpox & 0 & -4.9346 & 8.695891 & 5.611996 & 6.186948 & 2.783956 & -0.99954 & 9.90916 & 21.38376 & 26.862 \\
\hline
\end{tabular}

[CHART]

\begin{tabular}{lllllllllll}
\hline & 0 & 3 & 6 & 9 & 24 & 48 & 72 & 96 & 120 & 168 \\
\hline SAFA & 7.41 & 7.41 & 7.41 & 7.41 & 7.41 & 7.41 & 7.41 & 7.41 & 7.41 & 7.41 \\
UFA (nonOx) & 92.6 & 97.0 & 82.7 & 84.5 & 81.5 & 80.5 & 85.1 & 73.6 & 63.2 & 57.8 \\
PeroxAld & 0.519961 & 1.08836 & 1.678084 & 2.97248 & 5.37743 & 9.835649 & 9.010141 & 9.627194 & 8.497498 & 8.4855 \\
PolymEpox & 0 & -4.9346 & 8.695891 & 5.611996 & 6.186948 & 2.783956 & -0.99954 & 9.90916 & 21.38376 & 26.862 \\
\hline
\end{tabular}

\section{[CHART]}

\begin{tabular}{lllllllllll}
\hline & 0 & 3 & 6 & 9 & 24 & 48 & 72 & 96 & 120 & 168 \\
\hline SAFA & 7.41 & 7.41 & 7.41 & 7.41 & 7.41 & 7.41 & 7.41 & 7.41 & 7.41 & 7.41 \\
UFA (nonOx) & 92.6 & 97.0 & 82.7 & 84.5 & 81.5 & 80.5 & 85.1 & 73.6 & 63.2 & 57.8 \\
PeroxAld & 0.519961 & 1.08836 & 1.678084 & 2.97248 & 5.37743 & 9.835649 & 9.010141 & 9.627194 & 8.497498 & 8.4855 \\
PolymEpox & 0 & -4.9346 & 8.695891 & 5.611996 & 6.186948 & 2.783956 & -0.99954 & 9.90916 & 21.38376 & 26.862 \\
\hline
\end{tabular}

\section{[CHART]}

\begin{tabular}{llllllllll}
\hline & 0 & 3 & 6 & 9 & 24 & 48 & 72 & 96 & 120 \\
\hline SAFA & 7.28 & 7.28 & 7.28 & 7.28 & 7.28 & 7.28 & 7.28 & 7.28 & 7.28 \\
UFA (nonOx) & 92.7 & 96.3 & 94.3 & 82.6 & 83.6 & 80.0 & 77.5 & 37.9 & 47.0 \\
PeroxAld & 0.529955 & 1.933933 & 3.398602 & 3.977754 & 6.086895 & 6.252025 & 5.94197 & 5.845317 & 5.114452 \\
PolymEpox & 0 & -4.96017 & -4.40282 & 6.675658 & 3.556668 & 6.987762 & 9.838276 & 49.52335 & 41.12766 \\
\hline
\end{tabular}

[CHART]

\begin{tabular}{lllllllll}
\hline & 0 & 3 & 6 & 9 & 24 & 48 & 72 & 96 \\
\hline SAFA & 7.15 & 7.15 & 7.15 & 7.15 & 7.15 & 7.15 & 7.15 & 7.15 \\
UFA (nonOx) & 92.9 & 62.1 & 79.7 & 68.8 & 71.9 & 29.7 & 26.4 & 38.5 \\
PeroxAld & 0.516272 & 2.01787 & 2.962129 & 3.522127 & 4.179414 & 5.101263 & 4.711459 & 4.626553 \\
PolymEpox & 0 & 29.21546 & 10.67687 & 21.01115 & 17.24394 & 58.60888 & 62.22097 & 50.26113 \\
\hline
\end{tabular}

\section{Hosted file}

Figures 17.2.20-MTR2.docx available at https://authorea.com/users/299397/articles/428814alkyl-tail-segments-mobility-as-a-marker-for-omega-3-pufa-rich-linseed-oil-oxidativeaging 